\title{
A emergência do pensamento algébrico nas atividades de aprendizes surdos
}

\author{
The emergence of algebraic thinking \\ in the activities of deaf learners
}

\author{
Solange Hassan Ahmad Ali Fernandes ${ }^{1}$. \\ Lulu Healy ${ }^{1}$
}

\begin{abstract}
Resumo: Neste artigo, o foco é a emergência do pensamento algébrico. Busca-se, nos discursos de aprendizes surdos, compreender como eles articulam os meios de mediação disponíveis nas situações de aprendizagem matemática em um processo de transformar objetos conceituais culturais em objetos de consciência. Explora-se como os aprendizes, envolvidos ativamente em práticas interativas (tarefas e diálogos), podem pensar algebricamente, mesmo que ainda não estejam recorrendo a signos alfanuméricos. Essas interações ocorrem quando os aprendizes trabalharam com um conjunto de atividades analisando representações visuais de sequências numéricas e as modelando com o apoio do micromundo MATHSTICKS (um ambiente digital). Os exemplos apresentados neste artigo mostram evidências da presença das três características do pensamento algébrico apontadas por Radford - indeterminação, denotação e analiticidade. Além disso, as análises indicam que a criação de um signo compartilhado para representar a ideia de variável foi decisiva para o desenvolvimento do pensamento algébrico dos alunos.
\end{abstract}

Palavras-chave: Educação matemática. Aprendizes surdos. Inclusão. Pensamento algébrico. Ambiente digital de aprendizagem.

\begin{abstract}
This paper focusses on the emergence of algebraic thinking. It seeks to identify, in the discourse of deaf learners, the articulation of the meditational means available in carefully crafted mathematical activities in the process of transforming conceptual cultural objects into objects of consciousness. It explores how the learners, actively involved in interactive practices (tasks and dialogues), engaged in algebraic thinking without necessarily making use of alphanumeric signs. These interactions occurred as the learners worked through a set of activities, in which they analyzed visual representations of numerical sequences then modeled them using the tools of the Mathsticks Microworld (a digital environment). The examples presented in this article evince the presence of the three characteristics of algebraic thinking, described by Radford, indeterminacy, denotation and analyticity. The analyses also indicate that the creation of a shared sign to represent the idea of variable was decisive in the emergence of the students' algebraic thinking.
\end{abstract}

Keywords: Mathematics education. Deaf learners. Inclusion. Algebraic thinking. Digital learning environment.

\footnotetext{
${ }^{1}$ Universidade Anhanguera de São Paulo (UNIAN), São Paulo, SP, Brasil. E-mail: <solangehf@gmail.com>
} 


\section{Introdução}

Há um movimento latente em todos os segmentos sociais que se caracteriza pela necessidade de respeito às diversidades que compõem o contexto social e, naturalmente, esse movimento atinge as esferas educacionais. Nossas pesquisas envolvem um grupo de "diferentes" caracterizados por experimentar e interagir com o mundo de modo particular. No caso dos aprendizes surdos, por exemplo, estamos interessadas em compreender como as expressões visuoespaciais da língua de sinais, assim como as práticas interacionais associadas ao seu uso, moldam a apropriação do conhecimento matemático. Neste artigo, buscamos compreender como pessoas surdas usuárias da Língua Brasileira de Sinais (Libras) constroem significados matemáticos para a generalização de padrões. Em particular, questionamos como é que alunos surdos expressam generalidades matemáticas em Libras, e se esses modos de expressão evidenciam particularidades do pensamento algébrico.

Nossa abordagem tem sido fortemente influenciada pelo trabalho de Vygotsky. Especialmente por suas ideias sobre o papel mediador das ferramentas materiais e semióticas, desenvolvidas, sobretudo, a partir de estudos realizados com pessoas com deficiências (VYGOTSKY, 1997). Para ele, a linguagem é um conceito amplo que abrange, além da função comunicativa, a função de organização e de desenvolvimento dos processos de pensamento. No caso da criança surda, ele declara que, para superar os entraves causados pela ausência da língua oral, já no período pré-escolar, a criança desenvolve "hábitos mímico-gestuais" que representam mais do que um modo simples de expressar suas emoções e torna-se um meio vital de comunicação (VYGOTSKY, 1997).

As tendências educacionais atuais aproximam-se da visão de Vygotsky, ao considerar que as atividades linguísticas podem envolver diferentes modalidades, como, por exemplo, as línguas de sinais e as línguas orais. Basicamente, são dois os sistemas relacionados à produção e ao reconhecimento dessas línguas - o sistema sensorial, que utiliza recursos visuais, auditivos e vocais, e o sistema motor, que usa o corpo, mais especificamente as mãos, os braços e as expressões faciais. De acordo com Goldin-Meadow (2003), a modalidade manual é um meio tão bom quanto a modalidade oral. Isso sugere que a capacidade de criar e de aprender um sistema linguístico ocorre de modo independente de sua modalidade. Segundo a corrente soviética, tanto o pensamento quanto a linguagem são resultantes das interações entre indivíduos e seu meio sócio-histórico cultural (LEONTIEV, 1978; LURIA, 1992; VYGOTSKY, 1962). Seguindo essa corrente, Radford (2010a, p. 3, tradução nossa) declara que "o pensamento é uma forma sofisticada e versátil de ação, no qual os vários sentidos colaboram no decurso de experiências multissensoriais do mundo".

\section{O desenvolvimento do pensamento algébrico}

Neste artigo, nosso foco é a emergência e o desenvolvimento do pensamento algébrico e sua expressão em Libras. Mais especificamente, buscamos, nos discursos de aprendizes surdos, indícios de que atividades associadas às práticas discursivas favorecem a articulação dos meios de mediação disponíveis em um processo de transformar objetos conceituais culturais (objetos algébricos) em objetos de consciência. No desenvolvimento desse processo, os aprendizes, en- 
volvidos ativamente em práticas interativas (tarefas e diálogos), podem pensar algebricamente, mesmo que ainda não estejam recorrendo a signos alfanuméricos.

Orientando-se pela perspectiva vygotskiana, Radford e Roth (2011) discutem o pensamento como resultado de uma práxis reflexiva mediada pelo corpo, pelos signos e pelas ferramentas, ou melhor, como um movimento dialético entre uma realidade constituída histórica e culturalmente, e um indivíduo que reflete sobre ela e a modifica, de acordo com suas interpretações e sentidos subjetivos (RADFORD, 2006). Radford e Roth (2011), seguindo os passos de Leontiev, atribuem, a essas interpretações e sentidos, o caráter de sentido pessoal que, nas situações instrucionais, emerge da necessidade de distinguir o significado objetivo do significado individual atribuído ao objeto em estudo. Em outras palavras, durante a atividade, cada um dos participantes atribui um significado subjetivo ao objeto da atividade, que não corresponde, necessariamente, ao significado objetivo.

Neste texto, apresentamos episódios sobre os quais examinamos a interação entre um grupo de alunos surdos com atividades que envolvem generalização. Em cada episódio, procuramos evidências nas expressões dos alunos do pensamento algébrico, partindo da perspectiva de Radford (2014), que aponta que o pensamento algébrico é caracterizado por três elementos inter-relacionados - indeterminação, denotação e analiticidade. A indeterminação relaciona-se ao fato de que os problemas algébricos envolvem incógnitas ou elementos indeterminados, no nosso caso, números. Já a denotação relaciona-se à necessidade de nomear ou simbolizar o número indeterminado. Para Radford (2014, p. 4, tradução nossa), a denotação não envolve, necessariamente, o uso de padrões alfanuméricos, "quantidades indeterminadas podem também ser simbolizadas por meio da linguagem natural, gestos, sinais não convencionais ou até mesmo uma mistura destes". A analiticidade implica o tratamento, nas operações, com as quantidades indeterminadas como se elas fossem conhecidas.

De acordo com Radford (2010a), o processo de expressar as generalizações realizase em camadas de significação, não organizadas hierarquicamente, isto é, essas camadas não "estão arranjadas verticalmente", de modo que, ao se atingir uma delas, o caminho natural seja o ascendente. Para ele, essas camadas de significação estão "entrelaçadas com a forma material que usamos para raciocinar e expressar o geral (por exemplo, o sistema semiótico de padrão algébrico alfanumérico, a língua natural ou outra coisa)" (RADFORD, 2010b, p. 42, tradução nossa) e diferenciam a forma de pensar algebricamente do aprendiz. Cabe destacar que, segundo o autor, o pensamento é uma forma de reflexão e ação, que não se restringe ao cérebro, mas, também, envolve a coordenação semiótica sofisticada da fala, do corpo, dos gestos, dos símbolos e das ferramentas (RADFORD, 2014).

Radford (2010a, 2010b) discute três formas ou camadas de significação do pensamento algébrico: o contextual, o padrão e o factual. O pensamento algébrico contextual apresenta um caráter essencialmente pragmático, ou seja, as generalizações mantêm estreita relação com o procedimento empírico. A coordenação rítmica dos gestos, das palavras e dos signos dirige-se a um contexto, ou seja, as "fórmulas" descrevem termos gerais de um determinado contexto, mas as variáveis são expressas explicitamente por termos como o "número da figura", por exemplo desse modo, a indeterminação é articulada a uma situação particular. Já o pensamento algébrico padrão caracteriza uma mudança radical no discurso. Os símbolos alfanuméricos, que passam a ser usados para expressar as generalizações, fazem parte de um sistema linguístico (algébrico) que Radford (2010a) classifica como artificial. No entanto, é exatamente isso que garante que 
essas generalizações possam ter significado e aplicação além da situação particular a partir da qual foram articuladas. O que no pensamento algébrico contextual é denotado por signos dêiticos ou icônicos, passa a ser designado por um sistema semiótico de signos alfanuméricos. Quanto ao pensamento algébrico factual (RADFORD, 2010a), este se estrutura a partir de situações e fatos concretos, permitindo que os aprendizes elaborem fórmulas para representar generalizações sem letras ou outras formas de expressar as variáveis explicitamente. Nesta forma de pensamento, a indeterminação apresenta-se tacitamente. $\mathrm{O}$ autor destaca ainda que:

Apesar de sua natureza aparentemente concreta, o pensamento algébrico factual não é uma forma simples de reflexão matemática. Ao contrário, [...] ele repousa sobre mecanismos altamente evoluídos da percepção e da coordenação rítmica sofisticada de gestos, palavras e símbolos. A apreensão de regularidade e a imaginação das figuras no curso da generalização resulta, e permanece ancorado, em um processo profundamente mediado mostrando assim a natureza multimodal do pensamento algébrico factual. (RADFORD, 2010a, p. 7, tradução nossa)

Em cada uma das três formas de pensamento algébrico, há elementos concretos e abstratos. O que diferencia uma das outras é a maneira pela qual a relação entre esses elementos é expressa. Na próxima seção, apresentamos indícios, nas práticas discursivas de aprendizes surdos, que apontam que o sentido pessoal atribuído ao objeto da atividade pode conduzir a uma generalização, ou seja, uma forma de pensamento algébrico carregado de signos semióticos que expressam a ideia de variáveis algébricas, mesmo sem, necessariamente, lançar mão de símbolos alfanuméricos.

\section{O procedimento empírico}

Orientando-nos pela Metodologia do Design Experiment (COBB et al., 2003), as atividades que temos desenvolvido para aprendizes surdos procuram explorar representações visuais de sequências algébricas que favoreçam práticas reflexivas e discursivas. Reflexivas no sentido de evocar interpretações pessoais, isto é, significados subjetivos que possam favorecer as práticas discursivas entre os aprendizes, levando-os a articular seus sentidos pessoais com estruturas algébricas, formuladas a partir de situações concretas (FERNANDES; HEALY, 2013). As atividades, discutidas neste artigo, foram desenvolvidas nas terceira e quarta sessões de um conjunto de cinco realizadas em dias distintos que tiveram, em média, noventa minutos de duração cada. Após cada uma das sessões, o grupo de pesquisa se reunia para analisar a eficácia das tarefas, orientando-se pelos propósitos dos estudos, e para avaliar a necessidade de re-design na tarefa subsequente. A turma envolvida nas atividades era composta por seis alunos surdos, com idades que variavam entre 18 e 31 anos, matriculados no nono ano do Ensino Fundamental de uma escola do município de Barueri, São Paulo, Brasil. Esta escola atende regularmente alunos com e sem deficiência auditiva em classes comuns; em particular, esta turma do período noturno era composta somente por alunos surdos. 
Nesta escola, a Libras é considerada a primeira língua do aluno surdo e a Língua Portuguesa escrita sua segunda língua (L2). No caso dessa turma, nas aulas de matemática, ambas as línguas são usadas simultaneamente: é realizada a instrução do professor em Libras (algumas vezes, por meio de um tradutor intérprete) e o trabalho é escrito em português. Durante as sessões, além do professor de Matemática da turma e da tradutora intérprete, estiveram presentes quatro outros pesquisadores. Três filmadoras foram posicionadas na sala de aula para gravar as interações dos participantes. Além disso, três das cinco sessões envolveram o uso de ferramentas digitais disponibilizadas em três laptops. Além disso, por meio de um software específico, as ações produzidas pelos alunos, durante a realização das atividades e apresentadas na tela do laptop, foram capturadas e gravadas. Em todas as sessões, os alunos trabalharam em duplas.

Nas duas sessões iniciais, os alunos surdos realizaram tarefas que envolviam a generalização de padrões usando papel e lápis. Embora eles tenham concluído as atividades com êxito, nossas análises apontam que, ao longo destas sessões, os alunos refletem um modo de pensar algebricamente, mesmo não recorrendo à língua algébrica convencional. Considerando o sentido de indeterminação citado por Radford (2010b) como um elemento crítico do pensamento algébrico, nossas evidências sugerem que nem as tarefas realizadas e nem as intervenções dos pesquisadores foram suficientes para estimular o uso de práticas que tornem visíveis objetos indeterminados. Analisando os dados, levantamos a hipótese de que, embora as atividades fossem propostas em linguagem natural (Libras), por meio de valores numéricos e visualmente, as relações matemáticas não foram destacadas por meios visuais. Mesmo assim, os alunos conseguiram desenvolver métodos que lhes permitiram calcular todos os casos específicos propostos. No entanto, salientamos que os alunos não sentiram necessidade de mencionar explicitamente o desconhecido na elaboração desses métodos. Detalhes sobre estas duas sessões são encontradas em Fernandes e Healy (2013). Nas sessões seguintes, optamos, então, por uma nova abordagem. Com a intenção de favorecer o reconhecimento visual dos padrões, escolhemos o micromundo MATHSTICKS (Figura 1), criado usando-se a linguagem de programação LOGO (ANHANGUERA, 2015).

Esse micromundo permite pensar sobre generalizações de padrões figurais com as quais podemos interagir de forma visualmente dinâmica. Originalmente descrito em Noss, Healy e Hoyles (1997), o MATHSTICKS foi planejado para incentivar os alunos a produzirem um procedimento variável que pode ser usado para gerar o conjunto de termos de uma determinada sequência. Os elementos das sequências são palitos, que são desenhados na área de trabalho quando os respectivos ícones são clicados, e que são posicionados na área de trabalho por meio dos ícones de salto. Quando a caixa "história" é ativada (ligada), as ações do usuário são registradas simbolicamente por meio da linguagem LOGO. Uma vez registrados, os comandos podem ser repetidos tantas vezes quantas forem necessárias para determinar um termo qualquer da sequência. No exemplo apresentado na Figura 1, variamos o valor de n de 1 a 4 para produzir cada um dos termos representados.

Neste artigo, discutiremos duas atividades. A primeira delas (Figura 2) tinha o objetivo de familiarizar os alunos com o micromundo por meio da exploração de suas funções. Para iniciarmos a atividade, reproduzimos, na lousa da sala, a tela que os alunos viam no computador, ao abrirem o micromundo. Eles trabalharam em duplas e foram orientados, pelos pesquisadores, a explorarem as diferentes ferramentas do micromundo e suas funções. 
Fernandes, S. H. A. A.; Healy, L.

Figura 1. O micromundo MATHSTICKS

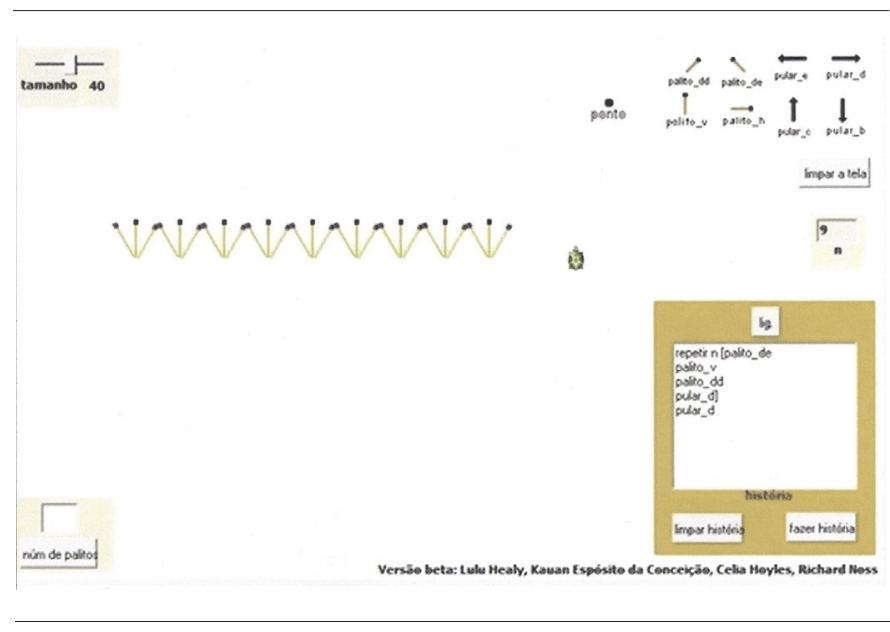

Fonte: Arquivo do grupo de pesquisa.

Figura 2. Atividade 1: Os "Ls"

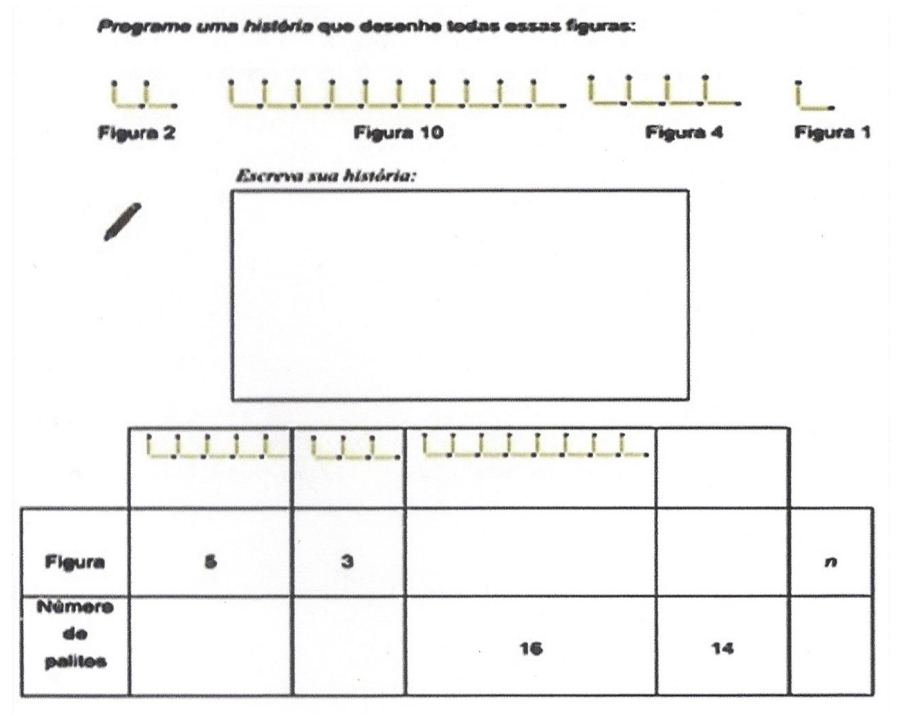

Fonte: Arquivo do grupo de pesquisa.

Em seguida, explicamos, aos alunos, que o objetivo da atividade era criar uma história que pudesse gerar os "Ls" e compor qualquer termo da sequência. Eles acompanharam os procedimentos indicados pelo pesquisador para a criação de um "L" de palitos, executando os mesmos procedimentos nos seus laptops. Ao final da primeira intervenção, os alunos tinham, no 
quadro "história" do seu computador, o registro dos comandos - palito_v; palito_h; pular_d. O próximo passo era fazer uma sequência com seis "Ls". Passamos, então, a discutir o comando "Repetir". Ao concluirmos este passo no quadro "história", os alunos tinham - repetir 6 [palito_v; palito_h; pular_d] (Figura 3). Após, a tarefa dos alunos era criar uma sequência com 15 "Ls".

Figura 3. Criando "Ls

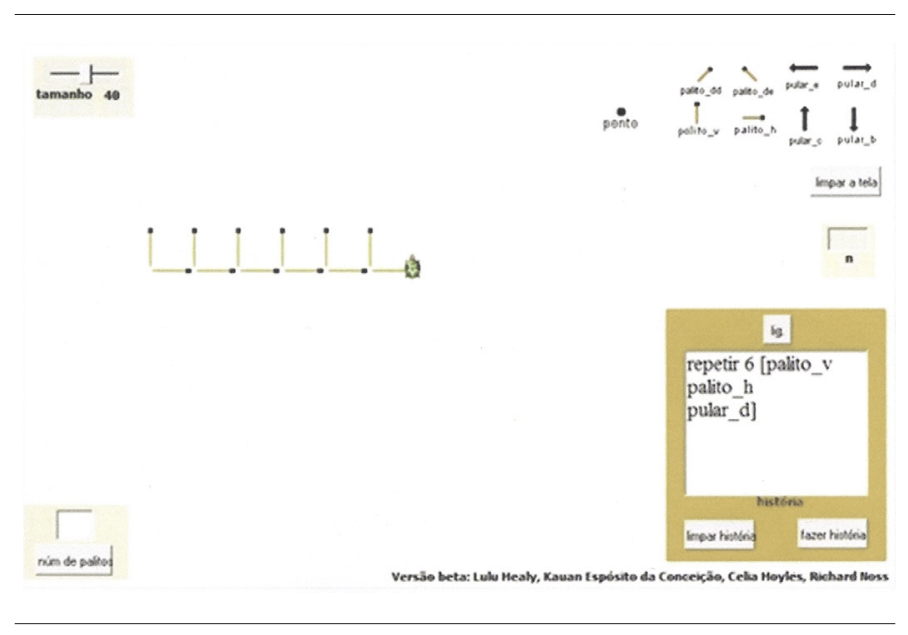

Fonte: Arquivo do grupo de pesquisa.

Pouco tempo depois e com relativa facilidade, os alunos concluíram a tarefa. Felipe (pseudônimo atribuído a um dos alunos) apresentou sua solução para todos (Figura 4).

Figura 4. "Repetir 15"

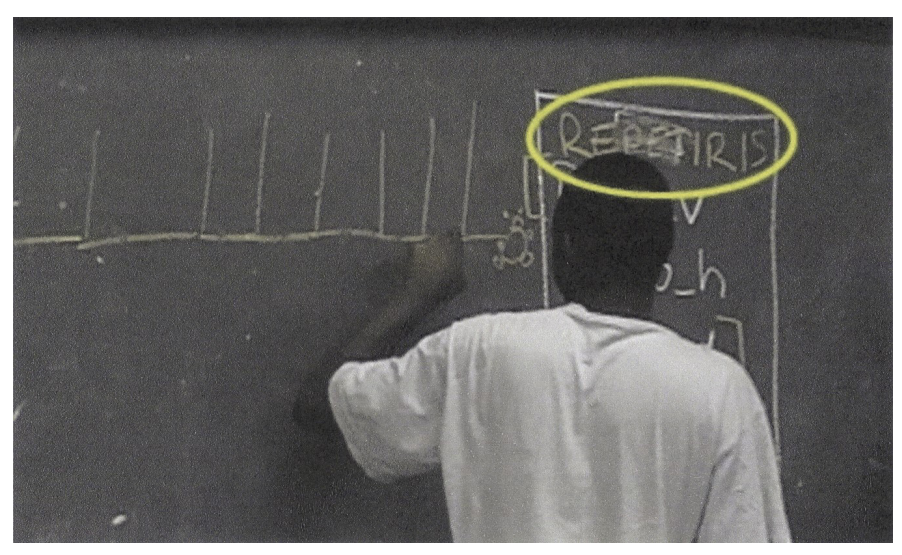

Fonte: Arquivo do grupo de pesquisa. 
Facilmente, os alunos compreenderam que poderíamos ver, na tela, uma sequência com a quantidade de "Ls" que quiséssemos, bastando trocar o número que acompanhava o comando "repetir". Desse modo, eles passaram a desenhar várias sequências com "muitos Ls". Com a intenção de introduzir o conceito de variável, chamamos "muitos L" de n, estabelecendo uma relação entre a quantidade de "L" desejadas na figura e a caixa denominada "n" no micromundo. Na caixa "história", passamos a ter - repetir n [palito_v, palito_h, pular_d] (Figura 5). Passamos, então, a discutir a quantidade de palitos necessária para construir cada uma das sequências representadas na atividade.

Figura 5. "Repetir n"

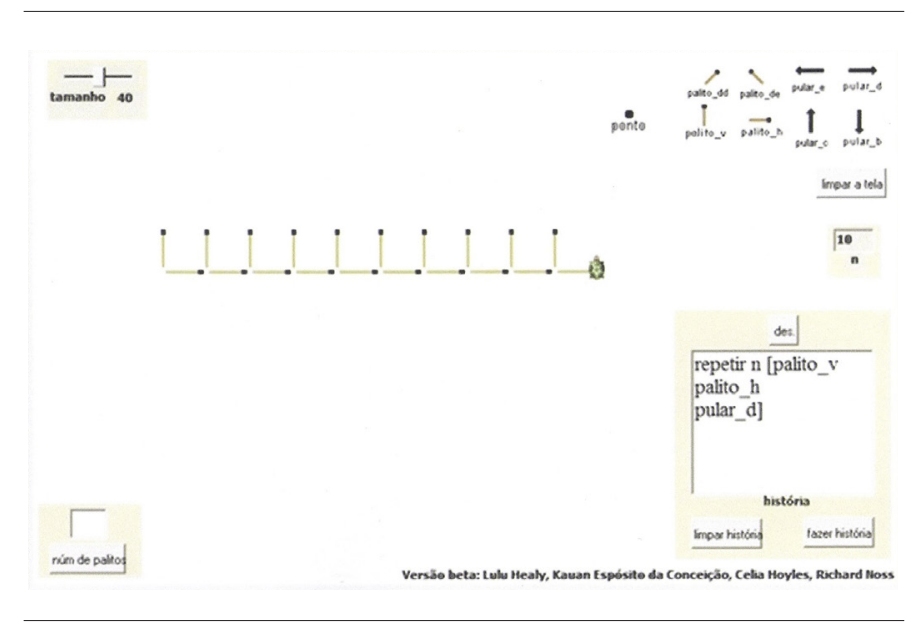

Fonte: Arquivo do grupo de pesquisa.

Após algumas tentativas e discussões, os alunos perceberam que, para determinar o número de palitos em uma sequência, bastava multiplicar o número de "L" por dois, uma vez que cada "L" era formado por dois palitos. A partir deste ponto, eles passaram a trabalhar em duplas e preencheram a tabela apresentada na atividade 1 (Figura 2). Depois de algum tempo, começamos a discutir coletivamente as respostas dadas por eles. Com facilidade, a tabela reproduzida na lousa foi completada até que chegássemos à coluna do n (Figura 6). Embora os alunos tenham percebido que, para cada " $L$ ", dois palitos eram utilizados, isso só lhes permitia resolver casos em que o número de "L" era conhecido. Tal fato nos leva a conjecturar que, nesta etapa, os alunos completavam a tabela contando o número de palitos, ou somando duas vezes o número de "L" na figura, ou, ainda, fazendo o número da figura multiplicado por dois.

Embora os alunos tenham variado o valor de $\mathrm{n}$ em suas interações com o MATHSTICKS, eles estavam pensando de forma predominantemente aritmética, operando com quantidades conhecidas. Nesses termos, o n atribuído por nós a "muitos L", na primeira parte da atividade, adquiriu o caráter de "um número conhecido" para eles. Discutindo os resultados, chegamos ao consenso de que, para se determinar o número de palitos, era necessário multiplicar a quantidade de "L" por dois sempre, e, assim, completamos a tabela escrevendo " $\mathrm{n} \times 2$ ". 
Figura 6. Completando a tabela

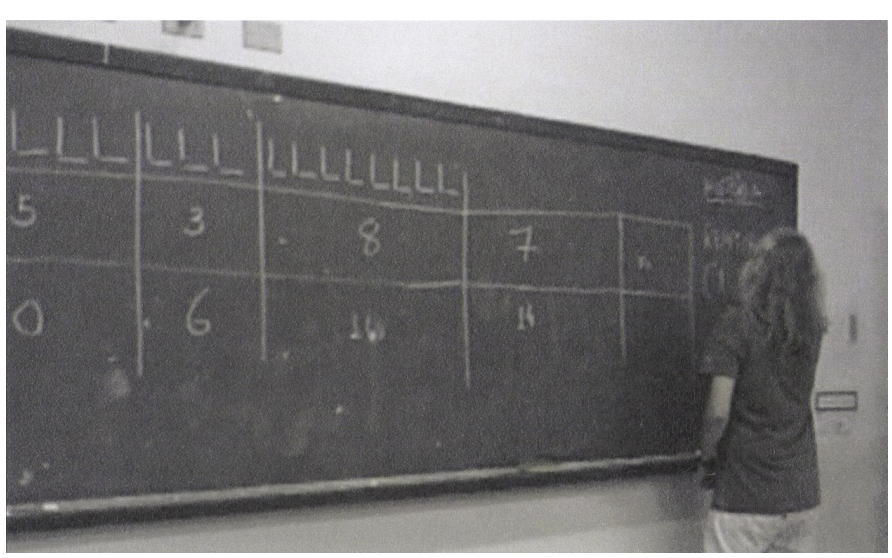

Fonte: Arquivo do grupo de pesquisa.

Naquele momento, refletindo sobre o que havia sido registrado na lousa, Elaine ofereceu uma nova interpretação para o n e sinalizou que "n é um número segredo" (Figura 7).

Figura 7. "Segredo" in Libras

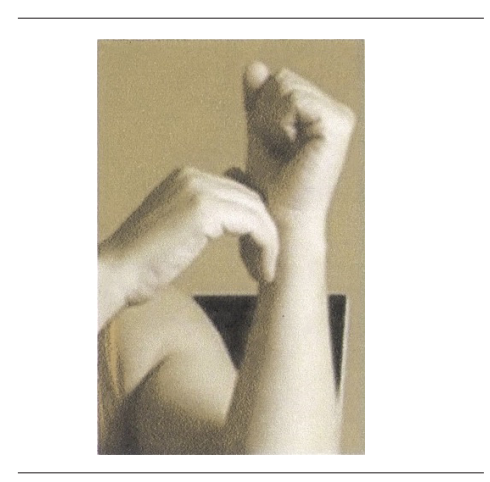

Fonte: Arquivo do grupo de pesquisa.

Ao analisarmos o discurso de Eliane, percebemos que a denotação da variável que ela nos ofereceu indica que ela desenvolveu um sentido pessoal de indeterminação e a possibilidade de operar matematicamente sem conhecer o valor dos números. Ao criar o sinal de "número segredo", Elaine expressou seu sentido pessoal para a variável n. A criação de sinais é um procedimento comum para aqueles que se comunicam em Libras, especialmente, porque sinais oficiais para termos matemáticos nem sempre existem ou, pelo menos, não são amplamente conhecidos. 
Neste caso particular, o processo envolvido na criação do sinal é denominado composição. E ele é descrito como sendo a combinação de dois outros sinais que dão origem a outro sinal (SÃO PAULO, 2008). Eliane combinou o sinal de número e o sinal de segredo que foi aceito e adotado pelos colegas. Nesta mesma sessão, os alunos trabalharam com outra sequência que lhes permitia determinar, de forma análoga, o número de palitos necessários para gerar determinado termo da sequência (Figura 8).

Figura 8. Uma nova tarefa

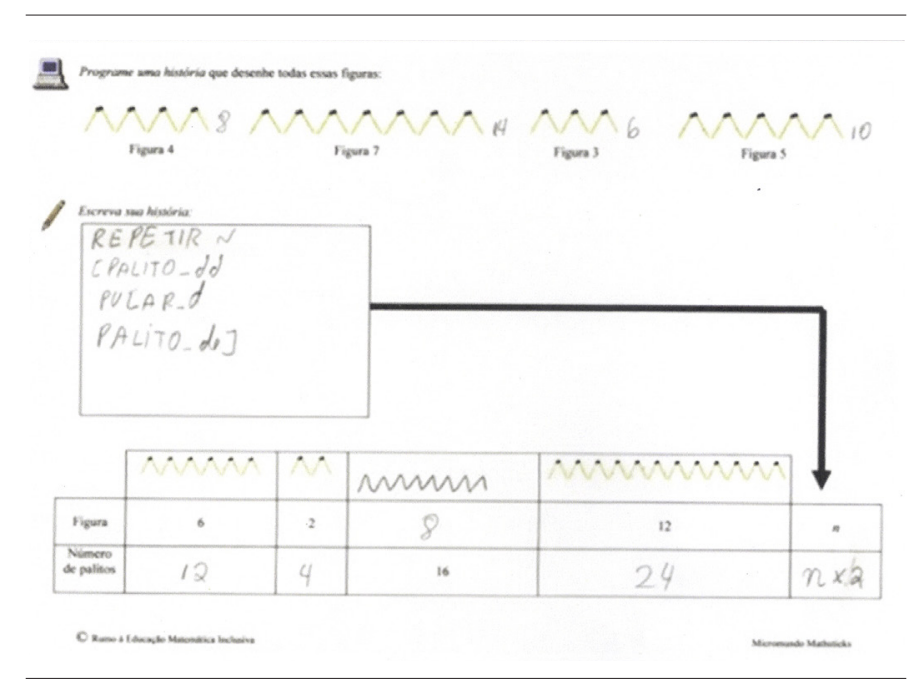

Fonte: Arquivo do grupo de pesquisa.

Nas análises das interações e do material produzido pelos alunos, encontramos indícios que sugerem que, nessa atividade, houve a emergência do pensamento algébrico contextual e do padrão. Os colegas de Eliane, apesar de compartilharem o sinal "número segredo", na expressão de suas generalizações mantêm estreita relação com o processo de desenhar as figuras, ou seja, com o procedimento empírico de características do pensamento algébrico contextual. Já para Eliane, o "número segredo", além de denotar a variável, indicava indeterminação e a possibilidade de "ser qualquer número". Em outras palavras, as ações e o discurso de Eliane apresentaram traços do pensamento algébrico padrão. Ela conseguiu compartilhar o sinal que criou com os colegas, mas não o sentido pessoal que atribuiu a ele.

$\mathrm{Na}$ sessão seguinte, os alunos trabalharam com atividades similares, no entanto, a complexidade da estrutura dos termos das sequências tornava-se gradativamente mais complexa. Na Figura 9, apresentamos um exemplo que chamaremos "a tarefa do retângulo".

Nas atividades anteriores, para escrever um termo geral, o procedimento que gerava a figura que constituía a sequência deveria ser repetido $\mathbf{n}$ vezes, ou seja, o termo geral era escrito da forma "repetir $\mathbf{n}$ [procedimento]". Nesta atividade, entretanto, o número de palitos horizontais variava, mas todos os termos tinham 2 palitos verticais, isto é, parte da sequência permanecia invariável. 
Figura 9. A tarefa do "Retângulo"

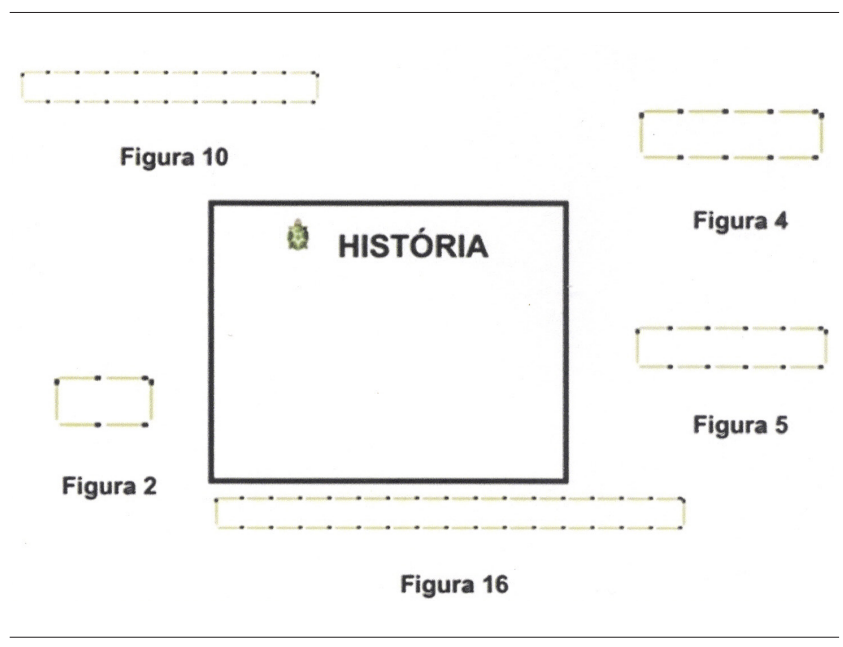

Fonte: Arquivo do grupo de pesquisa.

Não nos causou surpresa o fato de os alunos começarem a buscar generalizações que lhes permitissem aplicar a mesma estrutura que havia sido trabalhada nas atividades anteriores. Téo, por exemplo, percebeu quais eram os elementos da sequência que deveriam ser repetidos e, intuitivamente, escreveu repetir n [palito_h, pular_c, palito_h, pular_d, pular_h] na caixa história. Ao testar seus comandos, Téo percebeu que sua sequência estava incompleta, pois faltavam os palitos verticais (Figura 10).

Figura 10. Primeira tentativa

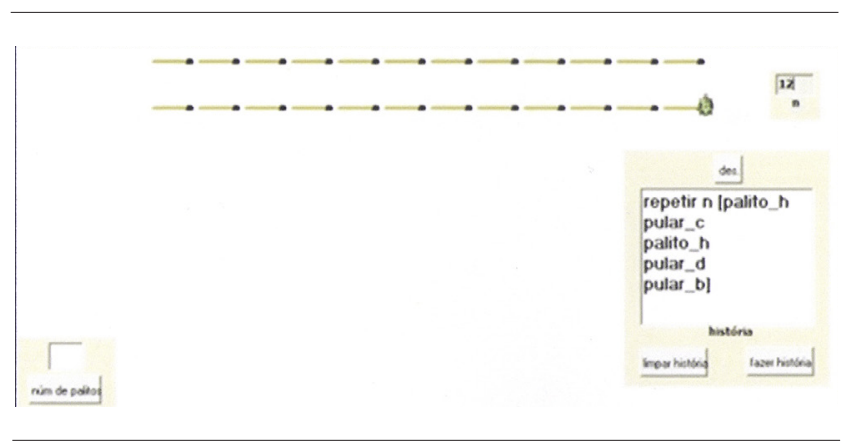

Fonte: Arquivo do grupo de pesquisa.

Para completar a sequência, ele acrescentou outros comandos em sua história: repetir n [palito_h, pular_c, palito_h, pular_d, pular_h], palito_v, repetir 12 [pular_e], palito_v, limpou a tela e executou o comando "fazer história". Ao ver a sequência que criou (Figura 11), mostrou-se satisfeito. 
Figura 11. Segunda tentativa

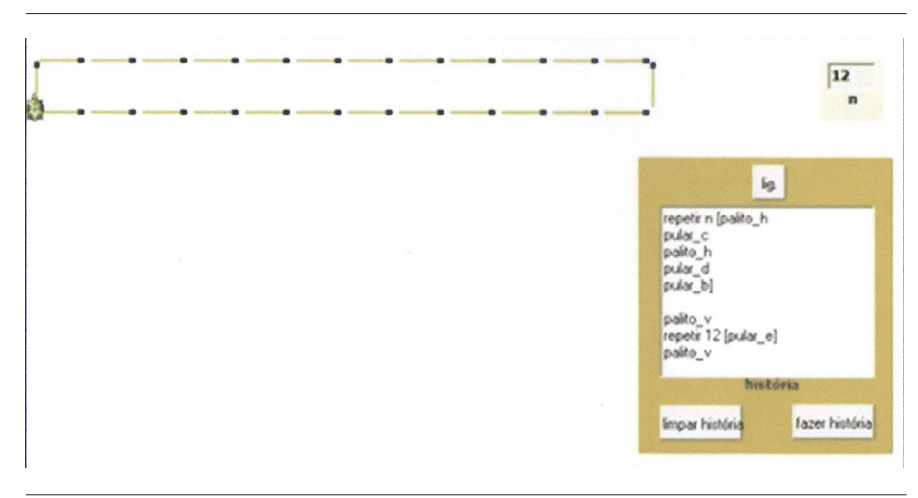

Fonte: Arquivo do grupo de pesquisa.

Pedimos que ele explicasse por que a alteração fez com que se formasse a sequência desejada, e, prontamente, ele sinalizou sua resposta:

12 aqui no $n$ [indicando a caixa $\mathrm{n}$ na tela]. Então repetir 12 [indicando 12 no quadro história]. Tem que ser igual a n. Um exemplo, se for 9 [indicando 12 no quadro história] vai dar errado. Tem que ser 12 para ficar igual. [Téo]

Para testar a validade de sua história para a determinação de qualquer elemento da sequência, pedimos que Téo criasse o vigésimo termo da sequência, o que gerou a sequência representada na Figura 12.

Figura 12. $\mathbf{n}$ igual a 20

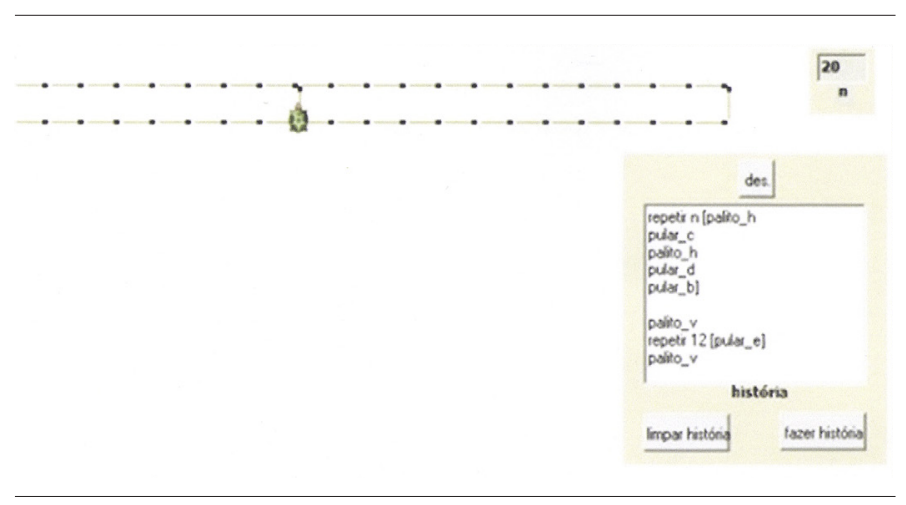

Fonte: Arquivo do grupo de pesquisa.

Ao ser questionado sobre a sequência que apareceu na tela, Téo afirmou que " $n$ diferente", e, para resolver o impasse, substituiu o número 12 pelo número 20 , o que fez a sequência correta (Figura 13). 
Figura 13. Repetir 20

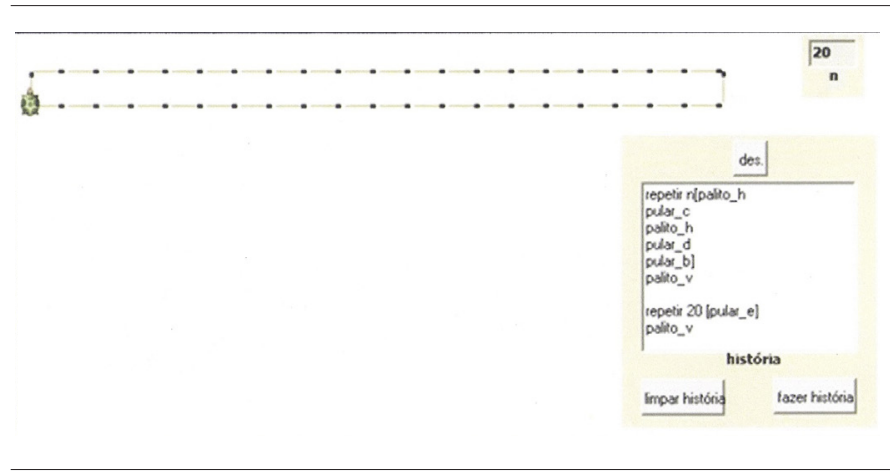

Fonte: Arquivo do grupo de pesquisa.

Perguntamos, então, se poderíamos ter uma história que gerasse qualquer elemento sem que tivéssemos que substituir manualmente o número na caixa história a cada vez. Após algumas discussões, Téo respondeu que sim, alterando sua história: repetir n [palito_h, pular_c, palito_h, pular_d, pular_h], palito_v, repetir n [pular_e], palito_v (Figura 14).

\section{Figura 14. Repetir $n$}
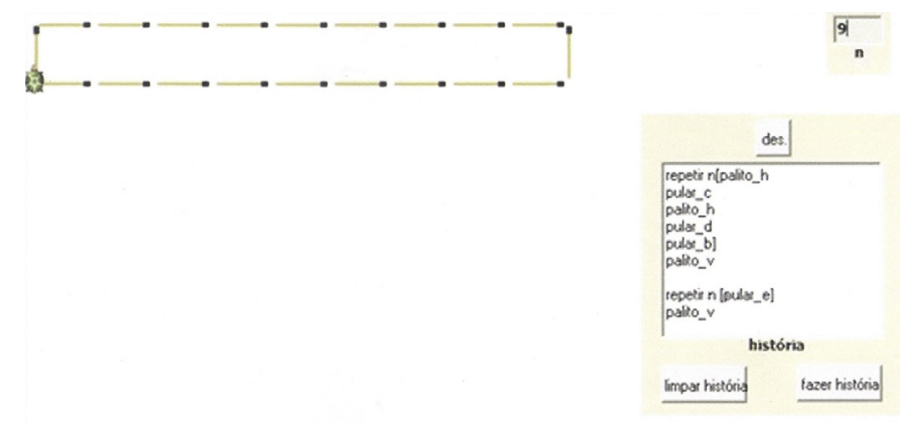

Fonte: Arquivo do grupo de pesquisa.

Fizemos algumas sequências para verificarmos a correção da estratégia e Téo afirmou que "sempre dá certo porque na caixa ne na história tem n (indicando ambas as posições)". No procedimento de Téo, podemos identificar traços da analiticidade proposta por Radford (2010a, 2010b) como uma das condições para o pensamento algébrico. Entretanto, devido à natureza da tarefa, o tratamento envolvia estabelecer relações entre termos gerais e específicos, no lugar de operar com incógnitas para localizar valores particulares. Esta operacionalidade poderia ficar mais evidente se a ideia de determinar o número de palitos necessários para formar cada termo da sequência tivesse sido mais explorada. 


\section{Reflexões sobre as generalizações dos alunos surdos}

Marschark e Hauser (2008, p. 9, tradução nossa), relatando acerca da importância da instrução mediada para os alunos surdos, afirmam que "o uso de recursos visuais dinâmicos acompanhando as descrições verbais dos instrutores são especialmente úteis para a aprendizagem". Inspiradas por esta perspectiva, planejamos as sessões discutidas neste artigo. A escolha dos elementos mediadores - micromundo, tarefas, intervenções e línguas usadas nas sessões - foi orientada para atender a particularidade e as preferências dos sujeitos de pesquisa.

Para isso, exploramos as representações visuais de um micromundo matemático interativo, considerando que essa forma de expressão poderia auxiliar no desenvolvimento de estratégias para generalizar padrões e, consequentemente, na emergência do pensamento algébrico. As representações dinâmicas oferecidas pelo micromundo MATHSTICKS permitiu, aos alunos, explorarem as estruturas visuais das sequências e encontrarem a possibilidade de gerar uma representação simbólica para um termo geral. Em nossas análises, buscamos indícios de que a interação dos alunos com o micromundo, com os seus pares e com o grupo os envolveu em um processo de coordenação de recursos corporais com signos linguísticos visuais e dinâmicos, a fim de atribuir significados para os objetos matemáticos.

Neste artigo, há indicadores de que os alunos foram conduzidos a uma práxis reflexiva mediada pelo corpo, pelos signos e pelas ferramentas, que promoveu mudanças no pensamento algébrico de acordo com as interpretações e os sentidos subjetivos que os alunos foram atribuindo aos objetos matemáticos. O primeiro exemplo desta prática, aqui apontada, relaciona-se ao significado subjetivo que Elaine atribuiu à variável n. Ao oferecer um sinal para a variável, compartilhado pelo grupo, ela pode ter proporcionado a todos uma reflexão sobre indeterminação. O "número segredo" passou a significar um valor não conhecido, mas com denotações particulares ligadas ao sentido pessoal atribuído ao termo.

O uso deste sinal pode estar associado à falta de familiaridade dos alunos com um sistema semiótico no qual objetos numéricos indeterminados podem ser expressos prontamente. A partir daí, no desenvolvimento das atividades, surgiu, no discurso do grupo, um sentido de indeterminação que, segundo Radford (2010b), é um elemento crítico do pensamento algébrico. Um exemplo é a primeira história oferecida por Téo para a "tarefa do retângulo" (repetir n [palito_h, pular_c, palito_h, pular_d, pular_h]), na qual ele mostra-se envolvido com este sentido de indeterminação. Os "muitos L" foram substituídos por "muitos palitos horizontais" (reconhecendo os elementos variáveis), mas tal procedimento acabou ocultando, para ele, os elementos invariáveis da sequência (os palitos verticais).

Já na segunda história proposta por Téo para esta mesma atividade (repetir n [palito_h, pular_c, palito_h, pular_d, pular_h], palito_v, repetir 12 [pular_e], palito_v), acreditamos que temos indicações do segundo elemento que caracteriza o pensamento algébrico - denotação (RADFORD, 2014). Téo usa, na mesma história, "repetir n" e “repetir 12", e conjecturamos que a simbolização do indeterminado é expressa por ele, nessa segunda tentativa, usando uma mistura de símbolos. Até este ponto, acreditamos que o aluno estava imerso no pensamento algébrico contextual, ou seja, suas generalizações estavam condicionadas ao procedimento heurístico.

Há traços da emergência do pensamento algébrico padrão quando passamos a discutir a validade da história de Téo para gerar qualquer elemento da sequência. Ele percebe a relação que existe entre a quantidade de palitos horizontais em uma linha da sequência e o número de pulos 
necessários para posicionar corretamente os palitos verticais, o que faz com que Téo reescreva sua história (repetir n [palito_h, pular_c, palito_h, pular_d, pular_h], palito_v, repetir n [pular_e], palito_v); ou seja, a discussão a respeito de uma situação particular o levou a desenvolver uma expressão para um termo geral do padrão e ele declarou que, para que o termo representado estivesse correto, era necessário que o número de repetições fosse igual ao número de pulos.

Concluímos acrescentando que, independentemente da língua usada, o desafio dos professores de Matemática é planejar cenários instrucionais nos quais os objetivos da atividade estimulem os alunos a se apropriarem dos elementos mediadores disponibilizados. Isso para que, desse modo, eles sejam conduzidos a uma práxis reflexiva sobre a realidade constituída histórica e culturalmente, e que construam suas próprias interpretações e sentidos subjetivos.

\section{Referências}

ANHANGUERA. Programa de Pós-Graduação em Educação Matemática. Rumo à educação matemática inclusiva. Disponível em: <http://www.matematicainclusiva.net. br/>. Acesso em: 27 out. 2015.

COBB, P. et al. Design experiments in educational research. Educational Researcher, Thousand Oaks, v. 32, n. 1, p. 9-13, 2003.

FERNANDES, S. H. A. A.; HEALY, L. Expressando generalizações em Libras: álgebra nas mãos de aprendizes surdos. Caderno CEDES, Campinas, v. 33, n. 91, p. 349-368, 2013.

GOLDIN-MEADOW, S. The resilience of language: what gesture creation in deaf children can tell us about how all children learn language. New York: Psychology Press, 2003.

LEONTIEV, A. Marxism and psychological science. In: Activity, consciousness, and personality. Englewood Cliffs: Prentice-Hall, 1978. p. 11-28.

LURIA, A. R. The child and his behavior. In: LURIA, A. R.; VYGOTSKI, L. S. Ape, primitive man, and child: essays in the history of human behaviour. New York: Harvester Wheatsheaf, 1992. p. 87-166.

MARSCHARK, M.; HAUSER, P. Cognitive underpinnings of learning by deaf and hard-ofhearing students: differences, diversity, and directions. In: (Ed.). Deaf cognition: foundations and outcomes. New York: Oxford University Press, 2008. p. 3-23.

NOSS, R.; HEALY, L.; HOYLES, C. The construction of mathematical meanings: connecting the visual with the symbolic. Educational Studies in Mathematics, Dordrecht, v. 33, n. 2, p. 203-233, 1997.

RADFORD, L. Algebraic thinking from a cultural semiotic perspective. Research in Mathematics Education, Abingdon, v. 12, n. 1, p. 1-19, 2010a.

. Elementos de una teoría cultural de la objetivación. Relime: revista latinoamericana de investigación en matemática educativa, México, número especial, p.103-129, 2006. Disponível em: <http://www.redalyc.org/articulo.oa?id=33509906>. Acesso em: 27 out. 2015. 
. Layers of generality and types of generalization in pattern activities. PNA:

pensamiento numérico avanzado, Granada, v. 4, n. 2, p. 37-62, 2010b. Disponível em:

<dialnet.unirioja.es/descarga/articulo/3122034.pdf>. Acesso em: 27 out. 2015.

The progressive development of early-embodied algebraic thinking. Mathematics

Education Research Journal, Dordrecht, v. 26, n. 2, p. 257-277, 2014.

RADFORD, L.; ROTH, W.-M. Intercorporeality and ethical commitment: an activity perspective on classroom interaction. Educational Studies in Mathematics, Dordrecht, v. 77, n. 2-3, p. 227-245, 2011.

SÃO PAULO (Cidade). Secretaria Municipal de Educação. Diretoria de Orientação Técnica. Orientações curriculares e proposição de expectativas de aprendizagem para educação infantil e ensino fundamental: Libras. São Paulo, 2008.

VYGOTSKY, L. S. Obras escogidas V: fundamentos da defectología. Madrid: Visor, 1997. The genetic roots of thought and speech. In: HANFMANN, E.; VAKAR, G. (Ed.). Thought and language. Cambridge: M.I.T. Press, 1997. p. 73-102. 